\title{
A critical analysis of CAPS for Life Skills in the Foundation Phase (Grades R-3)
}

\author{
Kerryn Dixon, Hilary Janks, Debbie Botha, Katarina Earle, \\ Manono Poo, Fiona Oldacre, Kamala Pather and Kerri-Lee \\ Schneider ${ }^{1}$
}

Corresponding author: Kerryn.Dixon@wits.ac.za

Wits University, Johannesburg, South Africa

(Received 1 August 2016; accepted: 9 May 2018)

\section{Abstract}

The Curriculum and Assessment Policy Statement Foundation Phase Life Skills curriculum (DBE, 2011) is composed of four focus areas: Beginning Knowledge; Personal and Social Well-being; Creative Arts; and Physical Education. These areas draw on a number of disciplines and this makes the curriculum dense. This density is, in turn, a challenge for teachers and teacher education. We perform an historical analysis of Life Skills curriculum documents from 1977 to the present and a content analysis of the CAPS document. Using Bernstein $(1971,1996)$ we show that this curriculum is weakly classified and that epistemological orientations are blurred, if not rendered invisible. The specificity of different disciplinary lenses that have different objects of enquiry, methods of analysis, and criteria for truth claims is lost in an overemphasis on everyday knowledge. If teachers are not themselves schooled in the languages of the disciplines that underpin Life Skills they may not be able to give children access to them, nor are they likely to be able to help them understand how different parts of the system relate to one another.

Keywords: Foundation Phase; Life Skills curriculum; teacher knowledge

\section{Introduction}

The Curriculum and Assessment Policy Statement (CAPS, DBE, 2011) for Foundation Phase has three subjects: Mathematics; Literacy; and Life Skills. The focus of this paper is Life Skills, which has four focus areas: Beginning Knowledge; Personal and Social Well-being; Creative Arts; and Physical Education. Figure 1 gives an overview of the Life Skills curriculum. Because these focus areas cover a great deal of content drawn from a number of disciplines, we argue that the Life Skills curriculum is too dense and that it presents a challenge for teachers and for teacher education.

This is a collaborative paper written by staff of the Foundation Studies Division in the Wits School of Education. All the authors contributed to the discussions about, and the writing of, this paper. Dixon and Janks are the first authors. 
None of us, as the authors of this paper, would describe herself as an expert in Life Skills or in the range of disciplines needed to teach Life Skills. However, this is undoubtedly also true of teachers in schools who are expected to be generalists capable of teaching across the Foundation Phase curriculum (Beni, Stears, \& James, 2017). Nor are we curriculum specialists with extensive knowledge of Bernstein's areas of expertise. Collectively, ours lies predominantly in language and literacy, and mathematics. As members of a Foundation Phase department, curriculum development is a shared responsibility for us and we have been concerned about how to improve the quality of the Life Skills component of our teacher preparation programme. While there are staff at the Wits School of Education with the disciplinary expertise to teach Life Skills, many lack experience with Foundation Phase.

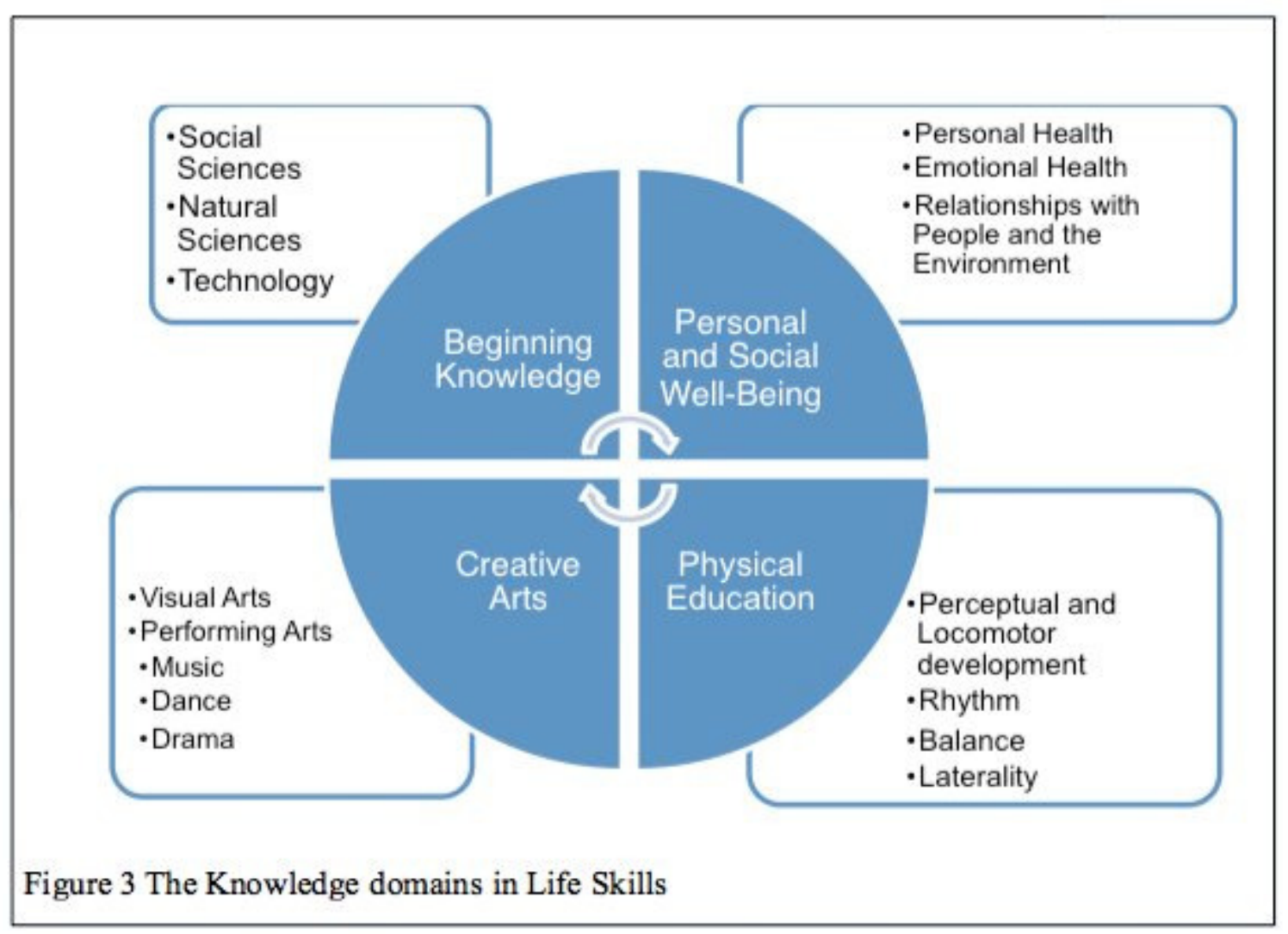

Figure 1 The four focus areas of CAPS Life Skills curriculum

We begin with a brief explanation of the Bernsteinian concepts used for our analysis and a discussion of other relevant literature. This is followed by a description of our research methods. We then explore the antecedents of Life Skills in order to understand how the density in the CAPS curriculum arose historically, and to make sense of how knowledge has been constructed in this subject over time. The current CAPS Foundation Phase Life Skills Curriculum and the specialist knowledge needed to teach Life Skills is examined. The article concludes with a discussion of the challenge the Life Skills curriculum poses for teachers and teacher education. 


\section{Key Bernsteinian concepts}

We use five key concepts from Bernstein's $(1971,1996)$ theory as analytic lenses: everyday and specialised knowledge; vertical and horizontal knowledge structures; and classification. ${ }^{2}$

Bernstein (1996) describes two types of knowledge-everyday knowledge and specialised knowledge. The former is context dependent, based on local events and practices, and is informed by subjective opinions rather than facts or established truths (Hugo, 2013). Specialised or school knowledge, as it is otherwise called, goes beyond people's feelings, experiences, and perceptions. It is attained from

an accumulation of different discoveries, inventions, experiments, calculations, and creations, [located in different disciplines] not acquired automatically through instinct or everyday living. (Hugo, 2013, p. 10)

Specialised knowledge thus differs from everyday knowledge in the specificity of its language. It is considered to be more powerful than everyday knowledge (Bernstein, 1999) because of its greater explanatory power and its ability to work at increasing levels of abstraction that can account for a wide range of phenomena.

Hugo (2013) recognises that the shift from everyday content to specialised concepts is not straightforward or linear. Drawing on Dowling's (1998) theory of specialisation, Hugo sees this as a transition from informal learning to more formal education. It is important to recognise that in the Foundation Phase everyday knowledge is still in formation and it is variable because of children's diverse backgrounds and pre-school experiences.

The distinction between everyday and specialised knowledge is particularly important for the Foundation Phase because teachers have to ascertain what everyday knowledge is in place. They need to fill the gaps in this everyday knowledge that children have, and they must introduce specialised knowledge. Because developmental conceptions of childhood, which question children's ability to work with abstract concepts, is dominant, it is important for the curriculum to specify what specialised knowledge young children need to develop. Without this there is a danger that Foundation Phase teaching relies on everyday knowledge at the expense of necessary specialised knowledge. When there is too much emphasis on everyday knowledge systematic learning of the discipline is compromised (Hoadley \& Jansen 2009).

What counts as specialised knowledge is different in different school subjects that are located in different knowledge structures. Bernstein described different disciplines as having either a vertical or horizontal knowledge structure. In vertical knowledge structures, knowledge progresses with layers of increasing complexity, such that each layer is able to account for the layers below. There is a logical progression of ideas 'building up to a complex conceptual vocabulary that has an internally systematic logic' (Hugo, 2013, p. 10). Disciplines with

We wish to express our thanks to Lynne Slonimsky and Wayne Hugo. They both worked with us to help us understand Bernstein. Wayne Hugo spent two days talking with us about the paper in relation to his book, Cracking the Code to Educational Analysis (2013). 
horizontal knowledge structures grow by developing competing accounts of the objects of knowledge that are the focus of the discipline. Each of these accounts contributes to the specialised language of the discipline. Concepts within each discipline also operate at different levels of abstraction.

Classification is the strength of the boundaries between objects or categories, in this case between school subjects. Classification is strong or weak depending on the "degree of insulation" between them. Strong classification has well defined boundaries between the categories and there is strong insulation between them. Each category has "its unique identity, its unique voice, its own specialised rules of internal relations." In the case of weak classification there is less insulation between the categories, which have "less specialised discourses, less specialised identities, less specialised voices" (Bernstein, 1996, p. 7). For our purposes, what this means is that if the boundaries between school subjects is broken and they are not insulated from one another they are in danger of "losing their identity" (Bernstein, 1996, p. 6). Moreover, there is a danger that teachers are not required to know and understand the specialised discourses, rules, and internal relations of the different subjects.

\section{Literature review}

There is little research in South Africa that focuses specifically on Life Skills in the Foundation Phase. Sheldon's (2015) research in two Grade 3 classrooms found that teachers did not think that Life Skills was an important subject in the overall Foundation Phase programme nor did they take it very seriously. Krishna's (2013) research with Grade 1 teachers highlights a lack of training and support, and teachers struggling with content, planning, and assessment. Although she does not specifically draw attention to this, the data shows teachers' lack of specialised knowledge across disciplinary areas. This confirms the findings of Mosia (2011) who discovered that teachers find Life Skills difficult to teach because of inadequate preparation. The research of Beni et al. (2017) focused on Natural Sciences. They show that teachers avoided teaching natural science, lacked specialised content knowledge, and were unable to integrate it into other subject areas. Malan (2014) noted that the specialised knowledge required to teach musical understanding is not clearly delineated in the CAPS curriculum for a generalist Foundation Phase teacher.

Only Steyn, Schuld, and Hartell (2012) offer an analysis of the curriculum, but the main focus of their research is understanding how the Higher Education Institutions that educate teachers for the Foundation Phase, teach Life Skills. They argued that the "subject Life Skills makes provision for a non-academic subject within the South African school's curriculum" (p. 162).

They take their definition of life skills from the statement of the World Health Organisation (1999) that the focus is on the development of "psycho-social skills in a culturally and developmentally appropriate way" (p. 6). This view of life skills puts the emphasis on nonacademic, everyday knowledge and foregrounds only the Personal and Social Well-being 
focus area. The most important finding from this research is that Higher Education Institutions vary in

- Coverage - which aspects of the Life Skills curriculum are or are not taught;

- Time allocation - time given to those aspects of the curriculum covered; and

- Focus-which aspects are given a separate focus and which are integrated.

These point to the difficulty of covering a compressed curriculum during preservice teacher education.

There have been several analyses of the recent iterations of the South African curriculum: Bertram $(2009,2016)$ focuses on the history curriculum (see, too, Bertram \& Barath, 2011); Johnson, Dempster, \& Hugo (2015) analyse Biology in the Life Sciences curriculum; Peden (2015) analyses Education for Sustainable Agriculture in Agricultural Sciences; and Schudel (2014) focuses on Environmental Learning. With the exception of Schudel, none of these mention the Foundation Phase.

These reviews highlight the consequence of integration, the collapse of disciplinary boundaries and everyday and specialised knowledge in Curriculum 2005 (C2005, DoE, 1997). Although C2005 was driven by a social justice agenda, it perpetuated educational inequalities (Johnson et al., 2015) that resulted in substantial curriculum revisions (Revised National Curriculum Statement [RNCS], DoE, 2002), and CAPS (DBE, 2011)). Bertram (2011) and Schudel (2014) argue strongly that progressive pedagogies and integrated approaches require teachers to have a deep disciplinary knowledge. Their analyses show that CAPS appears to be a return to a more strongly classified teacher-centred curriculum. For the sciences, a vertical knowledge structure is evident (Johnson et al., 2015; Peden, 2015; Schudel, 2014). In the Further Education and Training CAPS History curriculum there is an increase in substantive knowledge (understanding space, place, and time) and procedural knowledge (the organizing ideas that shape historical thinking). However, Bertram (2016) notes that there is a lack of progression of procedural knowledge across these grades.

Despite the overall shift back to more strongly classified knowledge systems in CAPS, Life Skills remains characterized by integration and weak boundaries where teachers are required to integrate content and skills from subject areas through topics. Schudel (2014) gives the telling example of the topic "waste" in Grade 3 where learners must understand the following, and teachers require substantive and procedural knowledge to impart this.

- What happens to our waste [supporting a Natural Science understanding of issues of land pollution in informal dumping, air pollution in burning, and issues of space and leaching in burying]

- Re-using, Recycling, Reducing and knowing what can't be recycled [supporting a Social Science understanding of resource use]

- Recycling at home and at school [supporting a Life Orientation interest in citizenship]. (p. 108) 


\section{Research questions and research methods}

This article addresses three inter-related research questions each of which requires a different research method.

1. How did the Life Skills curriculum come to take the form that it does?

We developed a genealogy of the subject Life Skills, based on creating an archive of curriculum documents from 1977 to 2011, and analysing them. We were able to construct only a partial archive since it is difficult to find all the relevant curriculum documents.

2. How does the CAPS Life Skills Foundation Phase curriculum construct knowledge in this subject?

To answer this question, we analysed the CAPS document using critical content analysis. We analysed the content of each school term and then analysed the whole phase (Grade R-3). The school term analysis allowed us to read across all the focus areas to see what content knowledge teachers need to teach the content in each school term. The phase analysis looks across terms so that we could examine sequencing and pacing in each of the focus areas in each grade and across the grades.

The analysis was designed to enable us to see how the content of the different focus areas is configured in the curriculum; the relation of parts to the whole; whether the focus was on everyday or specialised knowledge; and whether or not this distinction was clear. The focus on the kind of knowledge - everyday or specialised — enabled us to consider what specialised knowledge teachers need to teach different aspects of a topic.

3. What specialist disciplinary knowledge do learners need to acquire in the Foundation Phase to prepare them for the demands of the Intermediate Phase?

Subject specialists from history, geography, visual arts, music, physical education, and science in the Wits School of Education were interviewed to establish what specialist knowledge should be developed by Foundation Phase teachers to prepare children to enter Grade 4.

\section{The historical formation of Life Skills from apartheid to today}

Before discussing the content of the CAPS Life Skills curriculum, it is important to understand where it comes from. Life Skills was not always Life Skills; it has a history. In this section we trace its origins from Christian National Education apartheid syllabi through C2005 (DoE, 1997) and the RNCS (DoE, 2002), to CAPS (DBE, 2011), the current curriculum, in order to understand its constitution as a subject (see Figure 2). This account traces the continuities and discontinuities that over time have resulted in the current 
compressed Life Skills curriculum. We then unpack and disaggregate this compression in order to understand the specialised knowledge demands placed on Foundation Phase teachers.

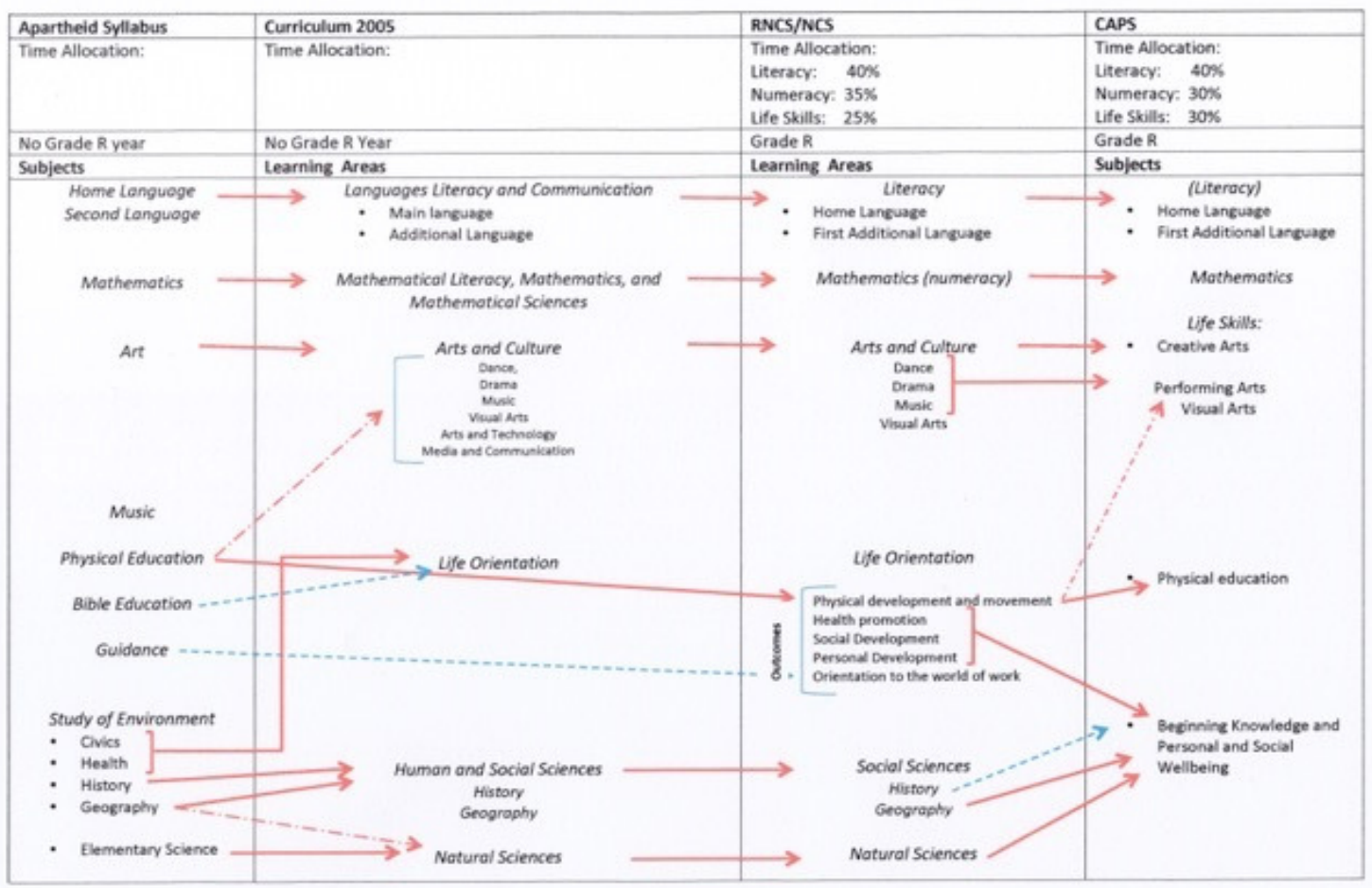

Figure 2 'Life Skills' Curriculum from Apartheid to CAPS

Our analysis of the Life Skills curriculum under apartheid is based on an archive that was available in the Wits School of Education library. ${ }^{3}$ It is important to note that a range of school subjects taught to children during apartheid now constitute Life Skills. The subjects we refer to here are drawn from the Transvaal Education Department's (TED) syllabus for white students. We know that education for different race groups served vastly different educational and political purposes (Hartshorne, 1992; Hyslop, 1999; Kros, 2010) deliberately retarding the development of the black population (Nkondo, 1979). In tracing the origins of Life Skills we see sufficient similarity between the Transvaal Education Department's curriculum for the first three years of school and CAPS for us to argue that this is a significant point of origination for Life Skills.

Figure 2 shows the subjects that children were taught in their first three years of formal schooling from the period 1977 to 2015. In addition to Languages and Mathematics, white children in Transvaal schools in 1977 were required to do Art, Music, Physical Education,

3 Transvaal Education Department syllabi for The Study of the Environment-Grade 1 to Standard 1 (1977), for Physical Education-Grades 1-2 and Standards 1-10 for Girls (1987), for Physical Education for Boys-Standards 1-5 (no date), Class Music-Grades 1-2 and Standards 1-4 (1978), Art Education-Grades 1 to Std 4 (1977) and the Manual for the Implementation of Guidance Programme-Grade 1 to Std 5 (1987). House of Assembly Schemes of Work for Bible Education (Grade 1, Grade 2 and Standard 1). It is not surprising the School of Education's library, formed while it was the Johannesburg College of Education responsible for training white teachers, does not have records of Department and Education and Training syllabi designed for Bantu Education. 
Bible Education, Guidance, and Study of the Environment. Each was constituted as one of six separate subjects with its own syllabus and specialist knowledge (see Figure 2, Column 1).

These separate syllabi indicate specific disciplinary content and sequencing determined by both the requirements of the knowledge domain and the notions of children's biological and social development held at that time. In Physical Education, for example, the content and sequencing are differentiated for boys and girls from Standard 1 (Grade 3).

Study of the Environment by way of contrast, was a composite subject comprised of Geography, History, Health Education, and Elementary Science (TED, 1977). These subjects have relatively strong boundaries and they divided into discipline-specific lesson units (e.g., historical stories and biographic studies, health habits, natural phenomena). The Christian Nationalist philosophy underpinning apartheid education is most apparent in the Study of the Environment syllabus where all themes need to stress that children must

1. be made aware of the majesty, beauty and order in God's creation and their sense of wonder must be stimulated

2. be led to a thankful and personal appreciation and acceptance of the gifts of God and the responsibilities of man [sic] to these gifts. (TED, 1977a, p. 2)

Deference to adult authority figures recurs throughout and so-called ethical standards require obedience to the teacher and compliance with the requirements of the group (TED, 1977a, p. 4). These manifest themselves in required child behaviour such as "co-operation, courtesy, personal neatness, helpfulness, consideration, faithfulness, steadfastness and responsibility" (TED, 1977a, p. 2), among others such as "mannerliness", "cleanliness", "respect", "national pride", "courage and devotion", and "tolerance for others" that are sprinkled throughout the document. Childhood is not seen as a state of being but one of becoming that needs to be actively shaped by adult supervision and moral surveillance.

The greatest curriculum shift is evident in the move from the apartheid curriculum to the model of outcomes-based education in C2005 (see Figure 2, Column 2). Disciplinary knowledges are reconstituted into Learning Areas, thus opening the boundaries between specialisations (Hugo, 2013). For example, Art and Music as apartheid subjects became components of the Arts and Culture Learning Area that also includes drama, dance, arts, technology, and media and communication. Components of the apartheid Physical Education syllabus, such as movement, moves to the Arts and Culture Learning Area while other components move to Life Orientation, thus splitting what was formerly a coherent body of knowledge.

According to C2005 the purpose of clustering subject knowledge into Learning Areas was "to encourage an integrated approach to learning" (DoE, 1997, Section 4.3), but this has serious disadvantages. The Arts are a good example; collapsing six disciplinary fields into the Arts and Culture Learning Area in the Foundation Phase is an example of weak classification that results in content overload. This overload remains in the next two Curriculum iterations (RNCS and CAPS; Columns 3 and 4). The disciplinary integrity of specialised fields of 
knowledge is compromised when they are no longer constituted as subjects but outcomes to be achieved in a limited amount of time, in a phase during which children are being introduced to specialised knowledge.

The constitution of Physical Education has also changed. No longer a separate subject in C2005, it re-emerges in the RNCS as physical development and movement (alongside health promotion, social development, personal development, and orientation to the world of work) and remains an outcome to be achieved (DoE, 2002). While it does not regain its status as a separate subject, Physical Education returns as one of four self-standing focus areas in Life Skills in CAPS (DoE, 2011; Column 4). Awareness of the importance of physical education and sports in schools has increased. Calls have been made to delink physical education from Life Skills (Cleophas, 2014).

It is interesting to see how Study of the Environment is reconstituted across these four curricula. Aspects of Civics and Health from the apartheid curriculum are incorporated into the Life Orientation Learning Area in C2005. Christian National Education is erased and references to religion are minimal. The suggestion is made in C2005 that religious education not be assessed (DoE, 1997, Section 4.5), thus lowering its status. Religion as a field of study is not developed as core to the Learning Areas in C2005, nor does it feature much in the RNCS or CAPS. It operates more at the level of everyday knowledge rather than specialised knowledge in the relatively superficial references to diversity, religious days, and holidays (DoE, 2011).

History and Geography, as well as elementary Science, are uncoupled from Study of the Environment in the apartheid syllabus and are given their own two Learning Areas in C2005 - Social Science and Natural Science. The disciplinary boundaries of geography are not solid (Hugo, 2013), straddling Social Science and Natural Science. While the disciplinary knowledge of geography remains in various configurations across the four curricula, history is systematically erased. ${ }^{4}$ History as taught through story and biographical studies in the TED curriculum is transformed in C2005 into a focus on indigenous knowledge systems, practices, and beliefs. In the RNCS much of this was written out. In CAPS the only explicit reference to history is a nine-hour unit in Grade 3 on how family and community lived long ago and a reference to inviting older members of the community to classrooms (DoE, 2011).

Perhaps one of the most striking aspects of the curriculum change is the construction of the child. The silent, respectful, obedient child of the apartheid curriculum is reconstructed as having far more agency. C2005's goal is to

provide children with opportunities to develop to their full potential as active, responsible and fulfilled citizens who can play a constructive role in a democratic, non-racist, and equitable society. The development of the child in totality should lead to a balanced personality so that he/she may be equipped with the necessary life skills. (DBE, 1997; Foundation Phase)

It is ironic that we are dependent on history in order to trace the origins of Life Skills in a curriculum that erases history, no doubt because of its use under apartheid to promote apartheid ideology. 
The child of the RNCS is not protected from social problems and is expected to know how to protect him/herself from communicable diseases, blood (read: possible HIV infection) and actively make the world a just and fairer place (DoE, 2002). Although much of this child agency remains in CAPS, in this more teacher-directed curriculum the actual child is backgrounded.

Over a period of nearly 40 years what emerges is a range of patterns. The apartheid curriculum's subjects are strongly classified. Even within Study of the Environment, Civics, History, Geography, and Science are clearly demarcated. This is in stark contrast to C2005 that aimed at integration. In many ways, the collapsing of disciplines into Learning Areas and the opening of boundaries between them was the start of the erosion of the specificity of disciplinary knowledge. Bertram (2009) also notes that in an outcomes-based curriculum knowledge is subsumed by outcomes describing skills and assessment standards. Thus, it is not always clear what constitutes specialised knowledge within Learning Areas.

Although the RNCS was streamlined, some Learning Areas are more coherent than others. Life Orientation is the least coherent. Here different subjects with their own specialised knowledges are compressed into one Learning Area. Subjects are also compressed into the Arts and Culture Learning Area. This continues in the Creative Arts focus area of Life Skills in CAPS, where art (now now called Visual Arts) is attached to the Performing Arts-dance, drama, and music. The Beginning Knowledge focus area is less coherent than Creative Arts, combining science and social science subjects: Geography; History; Science; and Technology. History, although mentioned, appears as a depleted placeholder. The consequences of combining subjects with vertical and horizontal knowledge structures in one focus area needs further interrogation.

Despite the explicit moves to change the school curriculum after apartheid ended, despite change across three iterations of curriculum, despite massive shifts in terminology and language, and despite different moves to open or close boundaries between subjects, many of the topics in the apartheid curriculum remain. Only religious education and history are more or less discontinued.

The general aims in CAPS stipulate that children will acquire, through explicit teaching outlined by the curriculum, particular yet meaningful knowledge and skills that they will be able to apply (DBE, 2011). Life Skills has traded subject-specific knowledge for a highly compressed amalgamation of knowledge domains. In addition, Life Skills, defined as a crosscutting subject, has responsibility for supporting and strengthening the teaching and learning of the Languages and Mathematics. Without an understanding of their history, the organising topics in the Life Skills curriculum appear to be incoherent and arbitrary.

It is clear that over time Life Skills has become the curriculum container for all subjects (other than Maths and Language) found in the preceding curricula. These subjects-History and Geography, Biology and Physical Science, Art, Drama, and Music, Physical Education, Health Education, and personal and social development apparent in the apartheid curriculum, were reconfigured into four Learning Areas in C2005: Social Sciences; Natural Sciences; 
Arts and Culture; and Life Orientation. Additional Learning Areas, Technology, and Economic and Management Sciences (EMS) were also included. In CAPS all these subjects, except for EMS, which was removed, have been compressed into Life Skills thus blurring the boundaries between them. They have been reconfigured as four sections or focus areas of Life Skills: Beginning Knowledge; Personal and Social Well-being; Creative Arts; and Physical Education (DBE, 2011).

Our analysis shows that in losing the specificity of disciplinary knowledge in these different focus areas, particularly Beginning Knowledge, and in collapsing Personal and Social Wellbeing into one focus area (DBE, 2011), and the creative arts into another, the boundary between everyday and specialised knowledge is weakened. In addition, the compression of all this curriculum content into Life Skills creates pressures and tensions that affect how teachers and teacher educators work with knowledge and pedagogy. We argue that despite weak classification in the Life Skills curriculum, teachers still require specialised knowledge of the school subjects that underlie the four knowledge domains in the CAPS Life Skills curriculum.

\section{The construction of knowledge in the Foundation Phase Life Skills curriculum in CAPS}

This section describes the four focus areas in the CAPS Life Skills curriculum to draw attention to the content overload. The content and concepts of Beginning Knowledge are taken from the Social Sciences, namely the disciplines of History and Geography and the key concepts for children to understand are conservation, cause and effect, place, adaptation, relationships and interdependence, diversity and individuality, and change. The disciplines of Biology and Physics underpin Beginning Knowledge in the Natural Sciences, which also require conceptual understanding. Concepts include life and living, energy and change, matter and materials, and planet Earth and beyond. Finally, Beginning Knowledge includes Technology. Both Technology and the Natural Sciences use methods of enquiry and analysis that range across observation, comparison, classification, measurement, experimentation, and communication. Technological process skills involve investigation, evaluation, communication, designing, and making.

The second focus area, Personal and Social Well-Being, draws from sociology (social health), psychology (emotional health and relationships with people), and Natural Science and Geography (human relationship with the environment) The specified content includes nutrition, diseases, safety, violence, abuse, and environmental health. This part of Life Skills endeavours to cultivate positive cultural, societal, and patriotic attitudes and values by educating children about their rights and responsibilities based on the Constitution.

Creative Arts, the third category in the Life Skills curriculum, is organised according to two parallel complementary streams - visual and performing arts. While visual art has its own stream, dance, drama, and music share the performing arts stream. Four specialised disciplines share this category of Life Skills with the added responsibility of developing 
children's fine and gross motor coordination as well as sensory motor skills. This is achieved, for example, in visual art, through manipulating material and mastering many art techniques.

The fourth category of Life Skills is Physical Education. In CAPS, Physical Education is once again separated from other subjects. There is no specification of concepts and the focus is on perceptual and locomotor skills that children must develop, including aspects such as rhythm, balance, and laterality. The separation here is surprising given that this focus is also the responsibility of all the focus areas, particularly the Creative Arts.

What we wish to highlight from this description is how knowledge has been reconfigured in the focus areas, and the nature of the boundaries between specialised knowledges. Strong boundaries are boundaries separating the focus areas (depicted as four separate boxes for four separate focus areas in Figure 1). Weaker boundaries exist between the knowledges in the focus areas, for example between the arts. Since the arts share some common features, this makes sense. Weak boundaries between the social sciences and the natural sciences make less sense since the sciences have vertical knowledge structures, but the social sciences tend to have horizontal knowledge structures.

What is less obvious but open to analysis is the rationale that underlies the division into these focus areas. The disciplines that constitute school subjects in the later phases of the curriculum are gathered together in Beginning Knowledge. History and Geography are the named social sciences that belong to Beginning Knowledge. Personal and Social Well-Being is more concerned with everyday knowledge, which is appropriate in the Foundation Phase given that everyday knowledge in relation to health, relationships, and the environment still needs to be consolidated. The underlying social science disciplines of psychology and sociology that teachers need in order to work with this category are rendered invisible. The creative arts are constructed as the space for creativity and the development of the physical and perceptual skills needed for engaging in creative activity-making and performance. Art, Drama, Music, and Dance are not conceived of as disciplines in this curriculum. Finally, Physical Education concentrates on developing children's perceptual skills as well as their fine and gross motor skills and their co-ordination. The knowledge of sports science, anatomy, and developmental psychology needed for teaching this focus area is not considered. It is therefore clear that the Life Skills curriculum concerns itself with what children need to know and it obscures the disciplinary knowledge that teachers need to have in order to teach this curriculum. This has huge implications for teacher education.

The density of the Life Skills curriculum, which depends on specialised knowledge drawn from a range of disciplines, mitigates against effective teaching. Without disciplinary knowledge, teachers are likely to focus on arbitrary unconnected facts rather than concepts, to rely on everyday knowledge, and to perpetuate misconceptions (Van Deventer, 2009). The lack of specialised disciplinary knowledge produces surface knowledge teaching instead of deep knowledge transfer (Hoadley \& Jansen, 2009). The boundaries that define subjects as particular disciplines with a unique set of principles undergirded by certain epistemological orientations are blurred, if not rendered invisible in the subject area Life Skills. The specificity of different disciplinary lenses that have different objects of enquiry, methods of 
analysis, and criteria for truth claims is lost. So too are the grammars that connect specialised concepts to one another to form a coherent system. If teachers are not themselves schooled in the languages of the disciplines that underpin Life Skills, they are not able to give children access to them, nor are they able to help them understand how different parts of the system relate to one another. There are no ordering principles and there is no logic of progression. Without access to concepts, children are more likely to draw on their common sense everyday knowledge, which, depending on their life experience, could be quite limited.

\section{Specialist knowledge that underpins Life Skills}

In order to understand the specialist disciplinary knowledge learners need to acquire in the Foundation Phase to prepare them for the demands of the Intermediate Phase, we interviewed disciplinary specialists in the Wits School of Education. We asked each specialist to respond to this question: "What skills, knowledge and attitudes do teachers need to teach children in the Foundation Phase, that will prepare them for learning your subject in the Intermediate Phase?"

Interviews were conducted with one lecturer from history, geography, visual arts, music, and physical education, and two from science. These interviews were rich with examples of the necessary discipline specific foundational concepts (e.g., from geography space and scale; from history stereotypes; from science mass and volume), procedures (e.g., observing, measuring, recording), and experiences (e.g., in science of "changing the properties of objects - hot to cold, solid to liquid, fast to slow"; in history thinking about events from different perspectives; in music singing). They also provided examples of the kinds of misconceptions that must be unlearned if teaching is based on everyday knowledge (e.g., that the night sky is static, that north is up, that the sun has to be drawn as a circle with spikes).

The themes that emerge from these interviews cut across the different focus areas and specialised knowledge domains. First is that it is more important to teach the basic concepts, skills, and dispositions that underpin a particular discipline than quantities of superficial factual knowledge. Factual knowledge can be acquired if and when it is needed. An example of this would be for children to understand that the world is round, and where South Africa is situated on the globe, rather than rote-learning the names of the nine provinces. This implies moving beyond everyday knowledge to core concepts, introducing concepts in a logical progression so that they build upon one another and lay a foundation to support work in the Intermediate and Senior Phases.

Second is the role of pedagogy. The lecturers agree that the young child needs to experience, observe, and experiment in a structured way, often beginning with the children's lives and their experiences, in order to develop the necessary skills, concepts, and dispositions. An example of this would be to have children make an outline of their bodies on paper and then compare this to a photograph, in order to develop concepts such as 3D/2D representation, scale, and symbolic representation. Another example would be to read stories from different 
perspectives such as the traditional tale of the Three Little Pigs versus A Wolf's Tale (Montanari, 1998), as part of developing historical literacy.

Finally, the lecturers all believe that developing children's conceptual understanding is underpinned by the teacher's own knowledge. Without some in-depth understanding of the core skills, knowledge, and attitudes required in a discipline, lessons depend on the rotelearning of facts, sometimes with incorrect concepts being entrenched. In other words, the teacher's own specialised knowledge in the disciplines of history, geography, science, and/or the arts is crucial. This specialised knowledge gives teachers the ability to focus on core concepts, make good choices regarding methodology, and move between specialised and everyday knowledge when needed (Bernstein 1996; Hugo, 2013). Krishna's (2013) research indicates that teachers are unable to do this. The Life Skills curriculum does not provide an outline or suggested sequence of the core concepts, skills, and attitudes required in each of these disciplines (see Malan's 2014 course outline for music), nor any guidance regarding teaching methods (Bernstein, 1996), a problem raised by Beni et al. (2017).

\section{The challenge of teaching Life Skills}

There are a number of challenges for teachers of Life Skills. The first and most important is acquiring the specialist knowledge needed to teach the content and discipline-heavy curriculum. It took us, an experienced group of Foundation Phase teacher educators and researchers, a long time to make sense of this highly compressed curriculum and this makes us wonder if teachers are able to unpack it in ways that go beyond seeing it as a list of topics to be covered. Just because the disciplines are backgrounded in the curriculum this does not mean that teachers do not need disciplinary knowledge. The range of disciplines that inform the Life Skills focus areas require teachers to have both depth in and breadth of the specialised knowledges that underpin these topics. If they do not have a wide range of specialist knowledges, they are likely to focus on unsystematically organised facts and content, rather than on concepts, languages, and procedures that have a logical progression internal to the disciplines that make up Life Skills.

Second, teachers have to understand the difference between everyday and specialised knowledge to support children's transition from experientially based understanding to a more systematised conceptual understanding (Hugo, 2013). One way of working with knowledge in the curriculum is to separate everyday experience and specialised knowledge (Hugo, 2013) so as to establish solid boundaries between them.

The placement of the Foundation Phase between the preschool years and the Intermediate Phase also affects the ways in which everyday and specialised knowledge are conceptualised. The differing ideologies and pedagogies of these phases contribute to the challenge. Education in the early years is usually underpinned by an informal approach to teaching and learning but during the Foundation Phase children need to be comfortable with a more formal and structured approach. Ideally, the Grade R year serves as a bridge between informal education, which promotes an emergent curriculum that foregrounds developmentally 
appropriate and contextually relevant practices (Excell \& Linington, 2011), and formal education (DBE, 2011) with more scientific context-independent activities and practices (Hugo, 2013) teachers have to negotiate the push from below of playful, experiential pedagogies, where incidental learning is firmly located in the everyday, and the pull from above of the Intermediate Phase where, for the most part, pedagogy is far more teacher directed and instruction orientated, where firm boundaries exist between specialised and everyday knowledge, and where the curriculum is strongly framed (House, 2011).

\section{The implications for teacher education}

That Foundation Phase teachers are generalists does not mean that when they are taught to work with disciplinary material they should be taught by generalist teacher educators. They need to be taught by disciplinary specialists so that they might become generalists with the expert knowledge they need to teach elementary knowledge across the disciplines. Preservice Foundation Phase Life Skills teachers should be able to research any topic from the perspective of different disciplines. They need an ability to imagine what would be of interest to a geographer, a historian, a scientist, or a technology expert with regard to topics such as transport or the seasons. Put more simply, they need to know what each of the disciplines can teach us about a topic and how to do the necessary research to teach the necessary elementary content. They need sufficient understanding of the grammar and ordering principles of the discipline to be able to work out which concepts, skills, and dispositions children need to develop to work with curriculum content and be able to help children pursue ideas in which they express interest.

Foundation Phase teachers must be able to provide children with the tools, the language, and the procedures they need to develop their ability to reason scientifically, creatively, historically and so forth, to apply their knowledge to a range of topics and problems. Where knowledge is presented as random bits of information on seemingly arbitrary topics, without system or logic, and where reasoning is not taught, children are forced to rely on rote learning. Education needs to produce students who can reason and think, and who are capable of independent, agentive work.

Teacher education has the onerous task of preparing Foundation Phase teachers to teach a wide range of subjects that require specialised knowledge. Most university qualifications limit the range of disciplines in which students can specialise to ensure sufficient depth of understanding. Foundation Phase teachers must have breadth in addition to some depth. It is simply not possible to cover all the content topics included in the Foundation Phase curriculum in teacher preparation courses. There is just too much, and there is no guarantee that these topics will remain stable. Instead, the focus should be on the disciplinary ways of seeing and reasoning, sufficient for teachers to do the research needed to prepare good lessons. Teachers have to understand enough of each discipline's language, tools, and concepts to investigate a topic using a range of disciplinary lenses. 
This is the challenge that confronts teacher educators charged with the responsibility of preparing teachers to work with the Life Skills curriculum and the challenge that confronts teachers already working in the system. How we all meet this challenge will determine whether or not children have a solid foundation on which to build the skills they need for life.

\section{References}

Beni, S., Stears, M., \& James, A., (2017). Foundation phase teachers' interpretation of the life skills programme with regard to the teaching of natural science. South African Journal of Childhood Education, 7(1), a440. Retrieved from https:// doi.org/10.4102/sajce. v7i1.440

Bernstein, B. (1971). Class, codes and control. London, UK: Routledge \& Megan Paul.

Bernstein, B. (1996). Pedagogy, symbolic control, and identity: Theory, research. London, UK: Roman \& Littlefield.

Bernstein, B. (1999). Vertical and horizontal discourses: An essay. British Journal of Sociology Education, 20(2), 157-173.

Bertram, C. (2009). Procedural and substantive knowledge: Some implications of an outcomes based history curriculum in South Africa. Southern African Review of Education, 15(1), 45-62.

Bertram, C. (2011). What does research say about teacher learning and teacher knowledge? Implications for professional development in South Africa. Journal of Education, 52, $3-26$.

Bertram, C. (2016). Recontextualising principles for the selection, sequencing and progression of history knowledge in four school curricula. Journal of Education 64, $27-54$.

Bertram, C., \& Barath, P. (2011). Specialised knowledge and everyday knowledge in old and new Grade 6 history textbooks. Education as Change, 15(1), 63-80.

Cleophas, F. (2104). Let's get moving on physical education. Retrieved from https://www.iol.co.za/news/opinion/lets-get-moving-on-physical-education-1728775

Department of Education. (1997). Curriculum 2005. Pretoria, South Africa: Department of Education.

Department of Education. (2002). Revised National Curriculum Statement. Pretoria, South Afrcia: Department of Education.

Department of Basic Education. (2011). Curriculum and Assessment Policy Statement $(C A P S)$. Pretoria, South Africa: Department of Basic Education. 
Dowling, P. (1998). The sociology of mathematics education. Mathematical myths/pedagogic texts. London, UK: Falmer.

Excell, L., \& Linington, V. (2011). Move to literacy: Fanning emergent literacy in early childhood education in a pedagogy of play. South African Journal for Early Childhood, 1(1), 1-23.

Hartshorne, K. (1992). Crisis and challenge: Black education 1910-1990. Oxford, UK: Oxford University Press.

Hoadley, U., \& Jansen, J. (2009). Curriculum: Organising knowledge for the classroom. Cape Town, South Africa: Oxford University Press \& SAIDE.

House, R. (2011). Too much too soon? Early learning and the erosion of childhood. Stroud, UK: Hawthorne Press.

Hugo, W. (2013). Cracking the code to educational analysis. Cape Town, South Africa: Pearson.

Hyslop, J. (1999). The classroom struggle: Policy and resistance in South Africa, 1940-1990. Durban, South Africa: KwaZulu-Natal Press.

Johnson, K., Dempster, E., \& Hugo, W. (2015). Exploring the recontextualisation of biology in the CAPS for Life Sciences. Journal of Education, 60, 101-121.

Krishna, A. (2013). From OBE to CAPS: Educators' experiences of the new life skills curriculum in the foundation phase (Unpublished MEd Report). University of KwaZulu-Natal, South Africa.

Kros, C. (2010). The seeds of separate development. Pretoria, South Africa: University of South Africa Press.

Malan, M. (2014). Musical understanding: An analysis of the creative arts CAPS outline for the foundation phase (Unpublished MEd report). University of Stellenbosch, South Africa.

Mosia, D. (2011). How secondary school teachers understand, respond to and implement life orientation (Unpublished Doctoral dissertation). University of Pretoria, South Africa.

Montanari, E. (1998). A wolf's tale. Albury, UK: Albury Books.

Nkondo, C. (1979). Comparison of the syllabus of the Bantu Education Department with that of the Transvaal Education Department and other related matters. Retrieved from http://www.disa.ukzn.ac.za/webpages/DC/rejul79.8/rejul79.8.pdf 
Peden, M. (2015) Education for sustainable agriculture: The old and new curricula for agricultural sciences in South African schools. Journal of Education, 60, 64-99.

Schudel, I. (2014). Exploring a knowledge-focused trajectory for researching environmental learning in the South African curriculum. Southern African Journal of Environmental Education, 30, 96-116.

Sheldon, M. (2015). Life skills in the foundation phase: A multiple case study into how life skills is enacted in two Grade 3 classrooms in Johannesburg (Unpublished master's research report). University of the Witwatersrand, South Africa.

Steyn, M., Schuld, N., \& Hartell, C. (2012). A bird's eye view on the status of the module "Life Skills' in the Foundation Phase at Higher Education Institutions in South Africa. South African Journal of Childhood Education, 2(2),158-176.

Van Deventer, K. (2009). Perspectives of teachers on the implementation of Life Orientation in Grades R-11 from selected Western Cape schools. South African Journal of Education, 29, 127-145.

World Health Organisation. (1999). Partners in Life Skills Education: Conclusions from a United Nations inter-agency meeting. Geneva, Switzerland: Department of Mental Health. Retrieved from http://www.who.int/mental_health/media/en/30.pdf 